\title{
Tests of thyroid function in vivo
}

\author{
A. W. G. GOOLDEN \\ From Hammersmith Hospital, London
}

During the past decade tests in vitro related to the the level of circulating thyroid hormone have been used to an increasing extent in the diagnosis of thyroid disorders. As a result less emphasis is now placed on thyroid uptake tests in vivo. It is relevant to consider, therefore, the role of these tests today and the part they are likely to play in the future.

\section{Indications for Thyroid Uptake Measurements}

Thyroid uptake tests are essentially kinetic tests which reflect the speed with which certain phases of thyroid hormone biosynthesis are taking place. Under equilibrium conditions the rate at which the thyroid accumulates iodine is closely related to the rate of production of thyroid hormone. The nature of the information provided by thyroid uptake measurements is different therefore from that obtained from the measurement of thyroid hormone levels. The two types of test, the one in vivo, the other in vitro, usually correlate with one another, but in certain circumstances, for instance, in patients treated with an antithyroid drug, this correlation no longer holds. Thyroid function is more likely to be assessed correctly when both types of test are utilized.

Thyroid uptake measurements have been used for monitoring thyroid function in patients undergoing treatment with an antithyroid drug (Alexander, Harden, and Shimmins, 1966; Alexander, Harden, Shimmins, McLarty, and McGill, 1967) and at the end of a course of treatment in order to find out whether a remission has taken place (Cassidy, 1965). In both instances the object of the investigation is to determine the underlying functional state of the gland rather than the amount of thyroid hormone being produced. In-vitro tests are inappropriate in these circumstances. Although tests carried out during treatment have proved less helpful in predicting the outcome than was anticipated (Alexander, McLarty, Robertson, Shimmins, Brownlie, Harden, and Patel, 1970; Lowry, Lowe, Hadden, Montgomery, and Weaver, 1971) they do give some indication of the likelihood of remission (Alexander, McLarty, Horton, and Pharmakiotis, 1973; Goolden,

Williams, and Thalassinos, 1973).

Thyroid stimulation and suppression tests have been carried out using circulating thyroid hormone ${ }_{\infty}^{\text {N }}$ levels as indices of response (Williams, Ekins, and $\omega$ Ellis, 1969a, and b) but thyroid uptake measure- i ments are generally preferred for this purpose $\vec{D}$

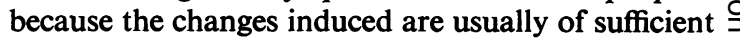
magnitude to be readily detected by in-vivo methods.

Thyroid uptake measurements are essential for establishing the identity of certain types of thyroid disorder and for studying the mechanism of action of drugs which interfere with thyroid hormone biosynthesis. Thyroid uptake measurements are also utilized in determining the therapeutic dose for patients being treated with ${ }^{131}$ I for thyrotoxicosis. It is often convenient in an outpatient clinic to have available a test which is completed within half an hour or so. This enables appropriate treatment to be started or a suppression test to be arranged when $\overrightarrow{\vec{A}}$ the patient is first seen. If advantage is taken of $\frac{0}{3}$ recent developments in methodology, the measurement of thyroid uptake is a simple procedure and certainly the quickest way of confirming a diagnosis of thyrotoxicosis.

\section{Measurement of Thyroid Uptake}

In principle the measurement of thyroid uptake is a fairly straightforward procedure. The patient is 음 given a test dose of a radioactive tracer and after a $>$ specified period of time the amount of radioactivity in the thyroid is measured with a suitable radiation $N$ detector. A comparison is made with an aliquot of the administered dose which is measured under 0 conditions which approximate as closely as possible $\underset{\omega}{N}$ to the conditions in vivo. Correction is made for various factors such as background radiation ando extrathyroidal radioactivity, and thyroid uptake is finally expressed as a percentage of the administered $\stackrel{\mathcal{P}}{+}$ dose. In practice all measurements in vivo of thyroid 70 uptake are subject to technical difficulties which vary according to the time at which the measurement is made.

In the past ten years or so increasing emphasis has been placed on early thyroid uptake tests. According 
to a recommendation made recently by the International Atomic Energy Agency (1972) the designation 'early thyroid uptake test' should be restricted to tests based on measurements made up to about 30 minutes after the intravenous administration of a radioactive tracer. Several factors favour early thyroid uptake measurements. First, tests carried out during the early phase reflect the speed of iodine metabolism much more reliably than tests carried out at a later stage. Secondly it is now generally acknowledged that the radiation dose to the thyroid is unacceptably high when ${ }^{131} \mathrm{I}$ is used, and one way of reducing the radiation dose is to use an isotope with a shorter half-life in which case the measurement of thyroid uptake has to be made within a few hours of administration of the isotope. Finally a number of workers have recently become interested in the measurement of thyroid uptake during treatment with an antithyroid drug; for this purpose it is necessary to use an isotope which measures the iodide-concentrating capacity of the thyroid or to carry out the test at a time when the measurement reflects iodide trapping rather than iodine binding.

The main problem associated with an early thyroid uptake measurement is that of finding a relatively simple and convenient method of correction for extrathyroidal radioactivity. Various methods have been described. Few if any of the methods which have been devised for measurements utilizing radioactive isotopes of iodine are satisfactory and some of them are too complicated to be suitable for routine use. Correction for extrathyroidal radioactivity is particularly important when ${ }^{99} \mathrm{Tc}^{\mathrm{m}}$ is used for measuring thyroid uptake because the concentration of radioactivity in the gland may not be greatly in excess of that in the surrounding tissues. Most workers have used scanning equipment for measuring ${ }^{99} \mathrm{Tc}^{\mathrm{m}}$ uptake. Using such methods the amount of ${ }^{99} \mathrm{Tc}^{\mathrm{m}}$ in the thyroid is derived from the net difference in dot density between thyroidal and extrathyroidal regions.

\section{Choice of Radioactive Isotope}

The choice of radiactive isotope and measurement technique for an early thyroid uptake test must take into account cost, availability, apparatus, ease of measurement, and radiation dose. Various radioactive isotopes have been used for measuring thyroid uptake (Goolden, Glass, and Silvester, 1968) (table I). ${ }^{131} \mathrm{I}$ is readily available from nuclear reactors at a reasonable cost but it is not ideal for diagnostic work and an isotope with rather different physical properties would be preferable. One disadvantage of ${ }^{131} I$ is that the resulting radiation dose to the thyroid is high, especially when compared with that delivered by other isotopes. ${ }^{125} \mathrm{I}$ is little better in this respect. ${ }^{132} \mathrm{I},{ }^{123} \mathrm{I}$, and ${ }^{99} \mathrm{Tc}^{\mathrm{m}}$ all give a small radiation dose to the thyroid gland and ${ }^{132}$ I has been extensively used for early thyroid uptake tests. However it emits high energy gamma rays which make it unsuitable for scanning so that problems associated with extrathyroidal radioactivity cannot be resolved by using the quantitative scanning techniques which have proved satisfactory for the measurement of ${ }^{99} \mathrm{Tc}^{\mathrm{m}}$ uptake. ${ }^{123} \mathrm{I}$ has physical characteristics which make it quite suitable in this respect but this isotope is not yet generally available. ${ }^{99} \mathrm{Tc}^{\mathrm{m}}$ is satisfactory in most respects and has been recommended in preference to radioactive iodine for the routine assessment of thyroid function (Goolden, Glass, and Williams, 1971). This recommendation has been endorsed by the IAEA panel on thyroid radionucleide uptake measurements (International Atomic Energy Agency, 1972). The radiation dose to the thyroid gland from ${ }^{99} \mathrm{Tc}^{\mathrm{m}}$, assuming an uptake of $2 \%$, amounts to $0.2 \mathrm{mrad}$ per $\mu \mathrm{Ci}$ administered.

\section{Use of ${ }^{99} \mathbf{T c}^{\mathrm{m}}$ for Measurement of Thyroid Uptake}

${ }^{99} \mathrm{Tc}^{\mathrm{m}}$ in the form of pertechnetate is concentrated in the thyroid, salivary glands, and stomach in the same way as iodide but it does not become organically bound in the thyroid and can be discharged by perchlorate, thus behaving in the same way as iodide in the thiouracil-blocked gland. Andros. Harper, Lathrop, and McCardle in 1965 showed that ${ }^{99} \mathrm{Tc}^{\mathrm{m}}$ could be used to measure the thyroid iodide concentrating mechanism or trap. These workers found that it was not possible to determine the uptake of ${ }^{99} \mathrm{Tc}^{\mathrm{m}}$ by the thyroid using methods similar to those employed in measuring ${ }^{131}$ I thyroid uptake because the neck background was high and

\begin{tabular}{|c|c|c|c|c|}
\hline Radioactive Isotope & Half-life & Average $\beta$ Emission (keV) & Predominant y Emission (keV) & 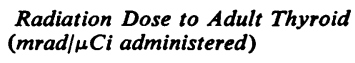 \\
\hline $\begin{array}{l}1^{23} \mathrm{I} \\
{ }^{123} \mathrm{I} \\
131 \mathrm{I} \\
132 \mathrm{I} \\
{ }^{9} \mathrm{~T} \mathrm{CE}^{\mathrm{m}}\end{array}$ & $\begin{array}{l}13 \text { hours } \\
57 \text { days } \\
8 \cdot 05 \text { days } \\
2 \cdot 3 \text { hours } \\
6 \text { hours }\end{array}$ & $\begin{array}{r}0 \\
0 \\
190 \\
490 \\
0\end{array}$ & $\begin{array}{rr}160 & \\
27 & \\
364 & \\
670 & 780 \\
140 & \end{array}$ & $\begin{array}{r}16 \\
1120 \\
1520 \\
17 \\
0.2\end{array}$ \\
\hline
\end{tabular}

Table I Principal physical properties of radioactive isotopes used in the investigation of thyroid disorders 
the thyroid uptake was relatively low, especially in normal subjects. Two alternative techniques were described. In one the uptake was obtained from the difference in the counts over the neck measured before and after the discharge of radioactivity by perchlorate. In the other method scanning equipment was used to determine the uptake.

Most workers have used scanning techniques for measuring ${ }^{99} \mathrm{Tc}^{\mathrm{m}}$ uptake. Such methods have commonly utilized a moving detector designed to produce the conventional rectilinear type of display (Shimmins, Hilditch, Harden, and Alexander, 1968; de Garreta, Glass, and Goolden, 1968) but the use of a stationary imaging device with the output in digital form has also been described (Hurley, Maisey, Natarajan, and Wagner, 1972). For moving detector devices either a single or a dual detector scanner may be used (Williams, Glass, Goolden, and Satyavarich, 1972). In the case of a rectilinear scan the dot density in two regions immediately above and below the thyroid region is determined and the information thus obtained is used to derive a value for extrathyroidal radioactivity in the area containing the thyroid image. Profile scanning techniques have also been used for measuring ${ }^{99} \mathrm{Tcm}^{\mathrm{m}}$ uptake (Tothill and Irvine, 1967) (Glass, Williams, and Goolden, 1972) and have been found advantageous over rectilinear methods in terms of speed and simplicity. More recently a method employing a stationary standard scintillation detector has been reported as giving satisfactory results (Van't Hoff, Pover, and Eiser, 1972). ${ }^{99} \mathrm{Tc}^{\mathrm{m}}$ uptake is generally measured at 20 minutes by which time a maximum uptake will usually have been reached.

Since the original report by Andros and others (1965) a number of workers have described their experience with ${ }^{99} \mathrm{Tc}^{\mathrm{m}}$ in the investigation of thyroid disorders (Atkins and Richards, 1968; de Garreta et al, 1968; Shimmins et al, 1968; Goolden et al, 1971; McGill, Harden, Robertson, and Shimmins, 1971 ; Höschl and Gimlette, 1971; Hurley et al, 1972; Van't Hoff et al, 1972). Published normal values for ${ }^{99} \mathrm{Tc}^{\mathrm{m}}$ uptake are in good agreement with one another (table II). In practice a ${ }^{99} \mathrm{Tc}^{\mathrm{m}}$ uptake has proved a satisfactory test for differentiating between hyperthyroid and euthyroid individuals (fig 1). The 20 -minute uptake of ${ }^{99} \mathrm{Tc}^{\mathrm{m}}$ has been found to

\begin{tabular}{lc}
\hline Author & Range (\%) \\
\hline Atkins and Richards (1968) & $0 \cdot 5-4 \cdot 0$ \\
De Garreta, Glass, and Goolden (1968) & $0 \cdot 4-3 \cdot 0$ \\
McGill, Harden, Robertson, and Shimmins (1971) & $0 \cdot 34-1 \cdot 51$ \\
Höschl and Gimlette (1972) & $0 \cdot 71-4 \cdot 12$ \\
Hurley, Maisey, Natarajan, and Wagner (1972) & $0 \cdot 24-3 \cdot 4$ \\
Van't Hoff, Pover, and Eiser (1972) & $0-4 \cdot 0$ \\
\hline
\end{tabular}

Table II Normal ranges for ${ }^{9}{ }^{9} \mathrm{Tc}^{\mathrm{m}}$ uptake at 20 minutes correlate well with the four-hour uptake of radio- $\underline{\text { O}}$ active iodine (Höschl and Gimlette, 1971) and it would seem that the magnitude of the iodide $\stackrel{\text { S }}{?}$ concentrating mechanism is a useful index of thyroido function. When serial tests of thyroid uptake are흘 required during treatment with an antithyroid drug $\overline{\bar{\rho}}$ it is preferable to measure the ability of the thyroid $\stackrel{\square}{\square}$ to trap or concentrate iodide because this functiong is not directly affected by drugs such as carbimazole which act at a later stage of thyroid hormone. biosynthesis. ${ }^{99} \mathrm{Tc}^{\mathrm{m}}$ is well suited for this purpose. $\vec{\omega}$ Burke, Halko, Silverstein, and Hilligoss (1972)@ found that in thyrotoxic subjects ${ }^{99} \mathrm{Tc}^{\mathrm{m}}$ could not? be completely discharged from the thyroid byin perchlorate but Shimmins, Harden, and Alexander ${ }_{\omega}^{\infty}$ 1969) were unable to demonstrate any significantio binding of ${ }^{99} \mathrm{Tcm}^{\mathrm{m}}$ by the gland. Our own observations $\vec{A}$ based on the discharge of ${ }^{99} \mathrm{Tc}^{\mathrm{m}}$ from the thyroido after an intravenous dose of sodium perchloratehave shown that the amount of ${ }^{99} \mathrm{Tc}^{\mathrm{m}}$ apparentlys bound under these conditions is so small that in practical terms it has very little significance.

In our experience the measurement of ${ }^{99} \mathrm{Tc}^{\mathrm{m}} \overrightarrow{\mathrm{\theta}}$ uptake has proved to be a reproducible procedure. Thyroid uptake was measured on two consecutive days in a series of 20 patients. For each patient the difference from the mean was calculated and expressed as a percentage of the mean giving an averagen value for the whole series of $7 \cdot 2 \%$ (Williams et al $\stackrel{\circ}{\mathrm{D}}$

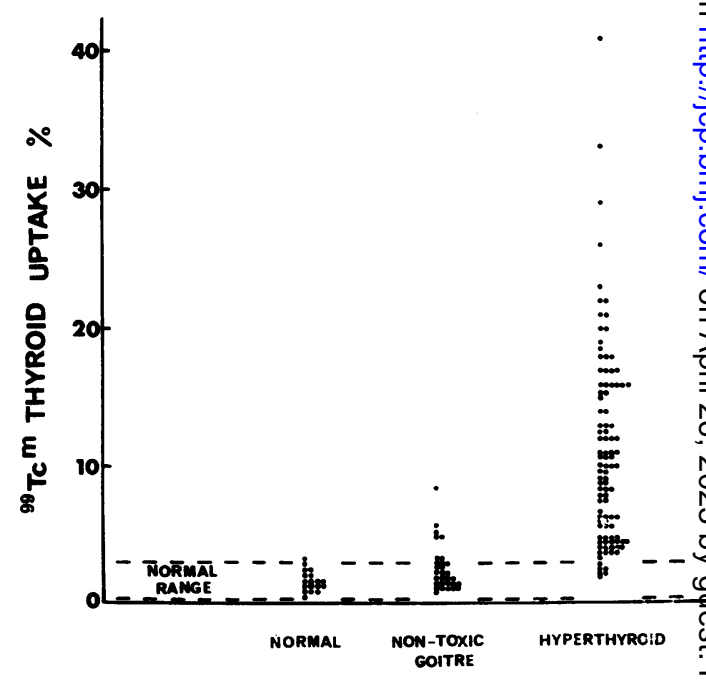

Fig 1 Values for ${ }^{99} \mathrm{Tc}^{\mathrm{m}}$ uptake in normal subjects (18) patients with non-toxic goitre (30), and patients with thyrotoxicosis (100).

(Reproduced from Goolden, Glass, and Williams, 1971, by courtesy of the Editor, Brit. med. J.) 


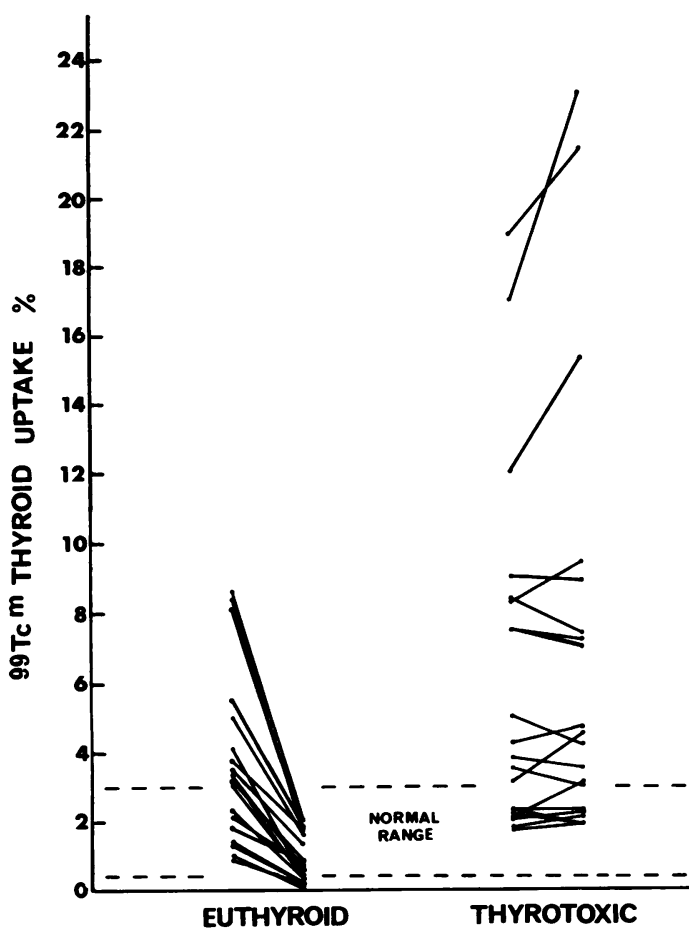

Fig 2 Suppression tests using ${ }^{99} \mathrm{Tc}^{\mathrm{m}}$ in euthyroid patients with non-toxic goitre or in remission from thyrotoxicosis (20), and in thyrotoxic patients (20)

1972). The reproducibility of the method is such that suppression tests can be carried out when necessary even when thyroid uptake is within the normal range. A fall in thyroid uptake of at least $50 \%$ of the initial value can be expected in non-toxic subjects (Goolden et al, 1968) (fig 2).

We are currently using a profile scanning method for measuring ${ }^{99} \mathrm{Tc}^{\mathrm{m}}$ uptake (Glass et al, 1972). This method, which utilizes a slit profile scanning collimator, gives results which do not differ significantly from those obtained by more complicated rectilinear scanning techniques. It is moreover much simpler and quicker to carry out. The result of the test is available within 30 minutes of giving the injection. The test can be carried out with a dose of $200 \mu \mathrm{Ci}$ of ${ }^{99} \mathrm{Tc}^{\mathrm{m}}$. The estimated radiation dose to the thyroid of a normal person from this procedure is $\mathbf{4 0} \mathrm{mrad}$.

\section{References}

Alexander, W. D., Harden, R. McG., and Shimmins, J. (1966) Thyroidal suppression by triiodothyronine as a guide to duration of treatment of thyrotoxicosis with antithyroid drugs. Lancet, 2, 1041-1043.
Alexander, W. D., Harden, R. McG., Shimmins, J., McLarty, D. and McGill, P. (1967). Development of thyroidal suppression by triiodothyronine during six months treatment of thyrotoxicosis with antithyroid drugs. J. clin. Endocr., 27, 1682-1689.

Alexander, W. D., McLarty, D. G., Robertson, J., Shimmins, J., Brownlie, B., Harden, R. M., and Patel, A. R. (1970). Predic tion of the long-term results of antithyroid drug therapy for thyrotoxicosis. J. clin. Endocr., 30, 540-543.

Alexander, W. D., McLarty, D. G., Horton, P., and Pharmakiotis, A. D. (1973). Sequential assessment during drug treatment of thyrotoxicosis. Clin. Endocr., 2, 43-50.

Andros, G., Harper, P. V., Lathrop, K. A., and McCardle, R. J. (1965). Pertechnetate-99m localization in man with applications to thyroid scanning and the study of thyroid physiology. J. clin. Endocr., 25, 1067-1076.

Atkins, H. L., and Richards, P. (1968). Assessment of thyroid function and anatomy with technetium-99m as pertechnetate. J. nucl. Med., 9, 7-15.

Burke, G., Halko, A., Silverstein, G. E., and Hilligoss, M. (1972). Comparative thyroid uptake studies with ${ }^{131} \mathrm{I}$ and ${ }^{\circ 9 \mathrm{~m}} \mathrm{Tc} 04$. J. clin. Endocr., 34, 630-637.

Cassidy, C. E. (1965). Use of a thyroid suppression test as a guide to prognosis of hyperthyroidism treated with antithyroid drugs. J. clin. Endocr., 25, 155-163.

de Garreta, A. C., Glass, H. I., and Goolden, A. W. G. (1968). Measurement of the uptake of ${ }^{9} \mathrm{~m}$ Tc by the thyroid. Brit. J. Radiol., 41, 896-898.

Glass, H. I., Williams, E. D., and Goolden, A. W. G. (1972). A simple rapid method for measuring the thyroidal uptake of ${ }^{\circ}{ }^{\circ} \mathrm{Tc}^{\mathrm{m}}$ by profile scanning. Brit. J. Radiol., 45, 680-683.

Goolden, A. W. G., Glass, H. I., and Silvester, D. J. (1968). The choice of a radioactive isotope for the investigation of thyroid disorders. Brit. J. Radiol., 41, 20-25

Goolden, A. W. G., Glass, H. I., and Williams, E. D. (1971). Use of ${ }^{9} \mathrm{Tc}^{\mathrm{m}}$ for the routine assessment of thyroid function. Brit. med. J., 4, 396-399.

Goolden, A. W. G., Williams, E. D., and Thalassinos, N. C. (1973). Studies of thyroid function using ${ }^{\circ}{ }^{\circ} \mathrm{Tcm}$ in thyrotoxic patients during treatment with antithyroid drugs. Clin. Endocr., 2, 65-73.

Höschl, R., and Gimlette, T. M. D. (1971). Diagnostic value of 20 minute ${ }^{\circ \mathrm{m} T \mathrm{Tc}}$ pertechnetate thyroid uptake. Nucl-Med. (Stuttg.), 10, 305-315.

Hurley, P. J., Maisey, M. N., Natarajan, T. K., and Wagner, H. N., Jr. (1972). A computerized system for rapid evaluation of thyroid function. J. clin. Endocr., 34, 354-360.

International Atomic Energy Agency (1972), Report: Thyroid radionuclide uptake measurements. Int. J. appl. Radiat., 23, 305-313.

Lowry, R. C., Lowe, D., Hadden, D. R., Montgomery, D. A. D., and Weaver, J. A. (1971). Thyroid suppressibility: follow-up for two years after antithyroid treatment. Brit. med. J., 2, 19-22.

McGill, D. E., Harden, R. McG., Robertson, I. W. K., and Shimmins, J. (1971). A comparison between the uptake of technetium-99m and iodine-131 by the thyroid gland. J. Endocr., 49, 531-536.

Shimmins, J. G., Hilditch, T., Harden, R. McG., and Alexander, W.D. (1968). Thyroidal uptake and turnover of the pertechnetate ion in normal and hyperthyroid subjects. J. clin. Endocr., 28, 575-581.

Shimmins, J. G., Harden, R. McG., and Alexander, W. D. (1969). Loss of pertechnetate from the human thyroid. J. nucl. Med., 10, 637-640.

Tothill, P., and Irvine, W. J. (1967). The use of technetium-99m for thyroid scanning and thyroid function testing. In Radioaktive Isotope in Klinik und Forschung, edited by $\mathbf{K}$. Fellinger and R. Höfer, p. 29.

Van't Hoff, W., Pover, G. G., and Eiser, N. M. (1972). Technetium-99 m in the diagnosis of thyrotoxicosis. Brit. med. J., 4, 203-206.

Williams, E. D., Glass, H. I., Goolden, A. W. G., and Satyavanich, S. (1972). Comparison of two methods of measuring the thyroidal uptake of ${ }^{\circ m}$ Tc. J. nucl. Med., 13, 159-164.

Williams, E. S., Ekins, R. P., and Ellis, S. M. (1969a). Thyroid suppression test with serum thyroxine concentration as index of suppression. Brit. med. J., 4, 338-340.

Williams, E. S., Ekins, R. P., and Ellis, S. M. (1969b). Thyroid stimulation test with serum thyroxine concentration as index of response. Brit. med. J., 4, 336-338. 